\title{
LOW BASAL METABOLISM FOLLOWING THYROTOXICOSIS
}

\author{
I. Temporary Type without Myxedema, with Special Reference \\ TO THE RôLe OF IODINE THERAPY ${ }^{1}$
}

By WILLARD OWEN THOMPSON,2 AND PHEBE K. THOMPSON ${ }^{3}$

(From the Thyroid Clinic and Metabolism Laboratory of the Massachusetts General Hospital)

(Received for publication November 25, 1927)

\section{INTRODUCTION}

In following cases of toxic goiter for the past two years we have been much impressed by the frequency with which low basal metabolic rates occur after thyroidectomy. During this time (1925-1927), basal metabolism below minus 15 per cent was observed in at least one-quarter of the cases of toxic goiter treated in this hospital. All such cases on record since the clinic began in 1914 were then collected. A study of the resulting data revealed some striking facts, one of which was that about half of these low rates were only temporary in duration, the other half being of the type which, by way of contrast, we call permanent. The corresponding clinical pictures revealed that about 65 per cent of the patients with permanent low metabolism and 90 per cent of the patients with temporary low metabolism were for the most part apparently normal individuals, showing neither signs nor symptoms of myxedema. ${ }^{4}$ The remaining patients showed clinical myxedema, ranging in severity from mild to full-blown.

For the sake of convenience, this study of low metabolism following toxic goiter has been divided into three sections, viz.,

1. Temporary low metabolism without myxedema.

2. Permanent low metabolism without myxedema.

\footnotetext{
1 This study was aided in part by a grant from the Proctor Fund of the Harvard Medical School for the Study of Chronic Diseases.

${ }^{2}$ Fellow of the National Research Council. Research Fellow in Medicine at the Harvard Medical School and at the Massachusetts General Hospital.

${ }^{3}$ Research Fellow in Medicine at the Massachusetts General Hospital.

"The term "myxedema" is used to denote any degree of true thyroid deficiency which is clinically discernible. It is not limited to the full-blown typical picture.
} 


\section{Myxedema. \\ a. Temporary type. \\ b. Permanent type.}

Sections 2 and 3 are dealt with in subsequent papers (1) (2). This paper is devoted to a study of the temporary type of low metabolism without myxedema, with special reference to the rôle that iodine therapy plays in its production.

\section{LITERATURE}

The only literature we were able to find with direct reference to temporary low metabolism following treatment for goiter was in a statistical report by Jordan (3) on basal metabolic rates and their relation to end-results in thyroid disease. She noted that a few cases of "benign goiter without hyperthyroidism" post-operatively showed an immediate drop in metabolism to below minus 15 per cent, but without clinical evidence of myxedema. These rates invariably rose later to normal without treatment. Eighteen cases or 3.3 per cent of a "primary hyperthyroidism series" had post-operative rates between minus 16 per cent and minus 27 per cent. Five only showed clinical signs of myxedema. The other thirteen cases "later had higher rates without treatment." No mention is made of whether there was coincident iodine therapy or not. Jordan suggests that the phenomenon is due to "an adjustment of function" of the thyroid gland.

\section{METHOD AND MATERIAL}

Basal metabolic rates were determined with the Roth-Benedict portable apparatus. Aub-DuBois standards were used in the calculations.

Included in this series are 27 patients with toxic goiter who showed a drop in basal metabolism following treatment to below minus 15 per cent-our actual range being minus 16 to minus 44 per cent-followed by a rise to the zone of plus or minus 10 per cent or higher The low metabolism was not accompanied by myxedema.

Table 1 gives an outline of the basal metabolic and clinical histories on those of the 27 patients on whom the data is not charted. 


\section{Time of onset and duration}

Although the time of onset of temporary low metabolism ranged from almost immediately after treatment to several years later, it is evident from table 2 that practically all the cases appeared during the first 4 months of convalescence, about half of this number occurring within the first month.

In 12 out of the 27 cases, only one low metabolism was observed, mainly due to the fact that at the time, no special interest was taken in this finding. For this reason it is difficult to make any very accurate general statement regarding duration. By calculating the time elapsing from the standard normal metabolism preceding the low rate to the one following it, it is possible, however, to state that in the great majority of instances the low metabolism did not last longer than 1 to 4 months. In a few cases the duration was somewhat longer than this. As is shown later, the length of these periods of low metabolism in many instances could be regulated at will by iodine administration.

\section{The striking absence of myxedema}

Temporary low metabolism following thyrotoxicosis, in general, is not associated with clinical evidence of myxedema. Out of 30 cases collected to date, 26 never had myxedema at any time: one (case 27 , fig. 4) had signs and symptoms suggestive of mild myxedema coincident with her first period of temporary low metabolism but no such signs or symptoms with three subsequent periods of temporary low metabolism. These 27 cases provide the material for this article. The 3 others, dealt with in the article on myxedema following thyrotoxicosis (2), had signs and symptoms suggestive of mild thyroid deficiency coincident with their period of temporary low metabolism, but later were symptom-free, although they again developed a low metabolism which as yet has not proved to be of the temporary type.

Given a low metabolism and that alone, one can not predict therefrom what the clinical picture will be with respect to the presence or absence of myxedema. Many of the patients in this series had as low a metabolism temporarily as is found in full-blown myxedema. For example, cases 1 (fig. 1), 2, 3, 4 (fig. 6), 5, 6, 7 (fig. 5), 8 and 27 


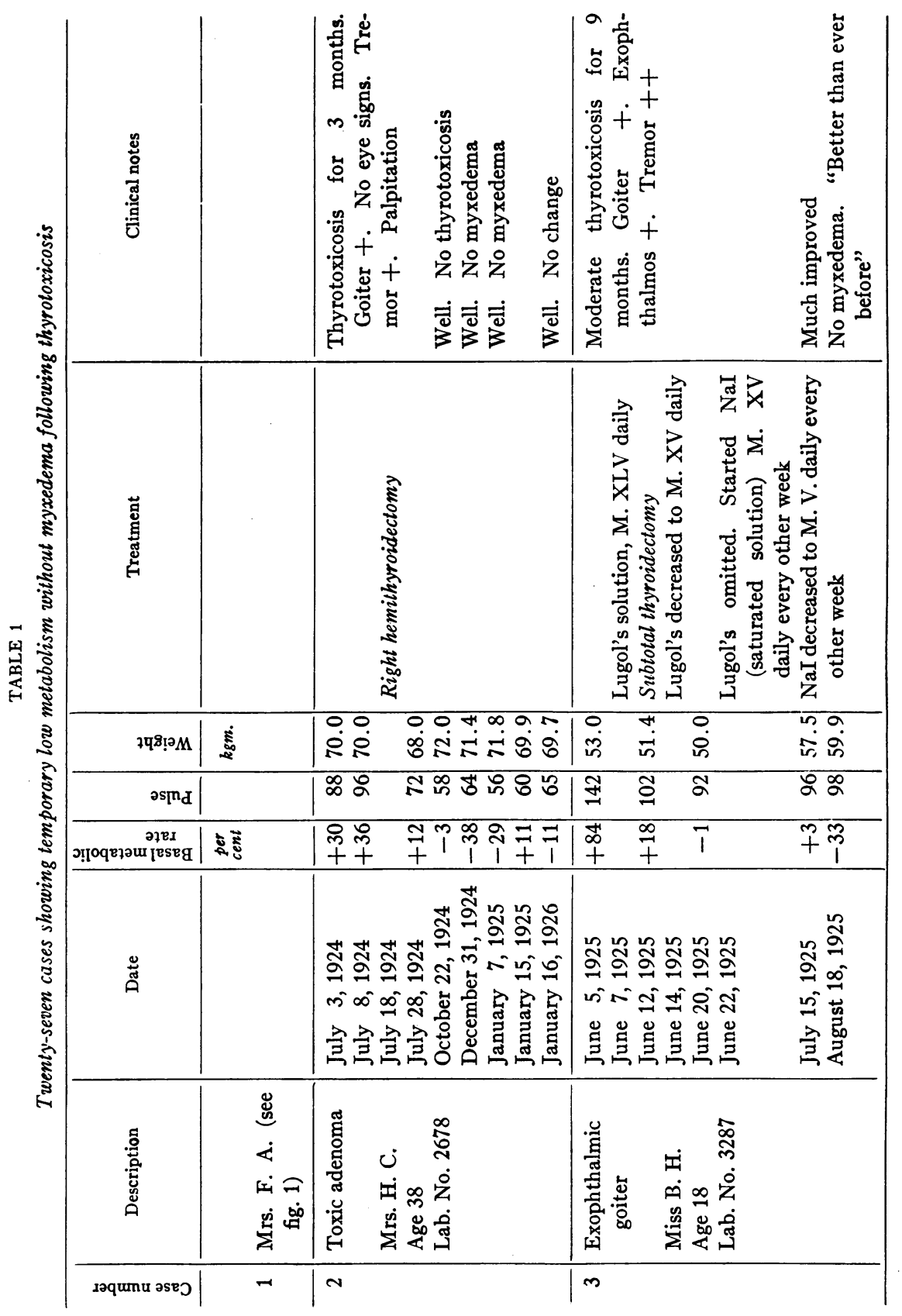


WILLARD OWEN THOMPSON AND PHEBE K. THOMPSON

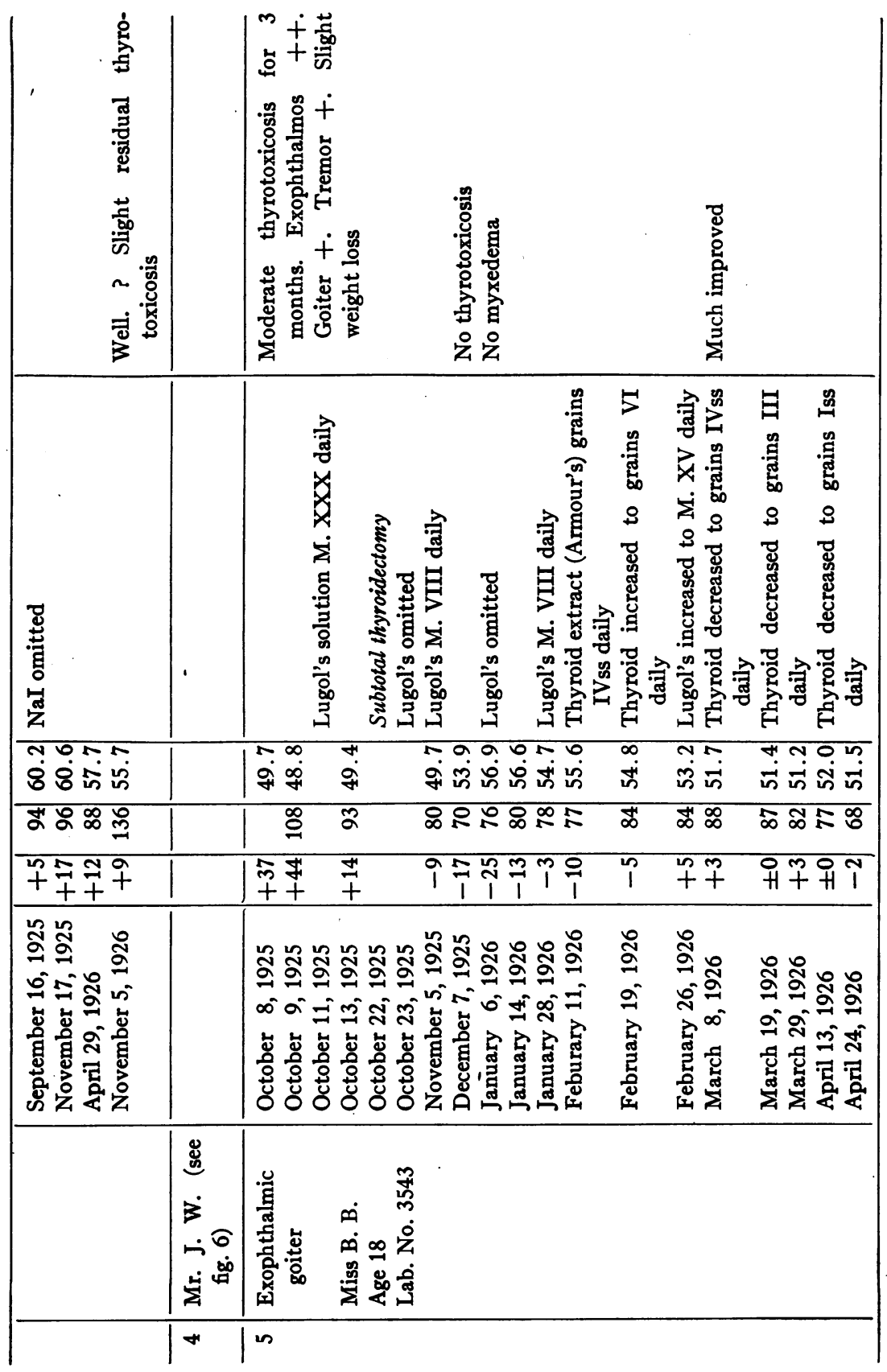




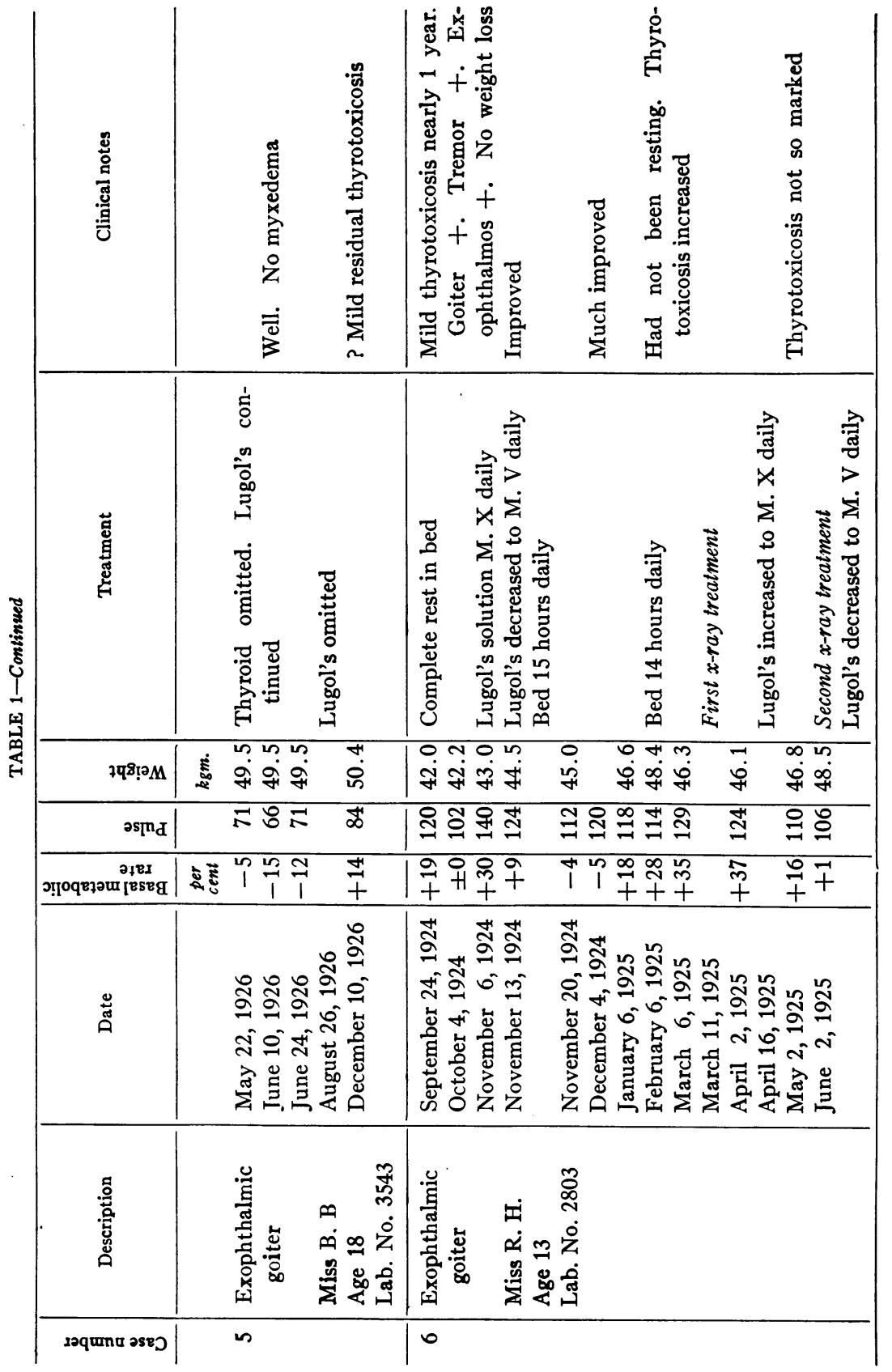




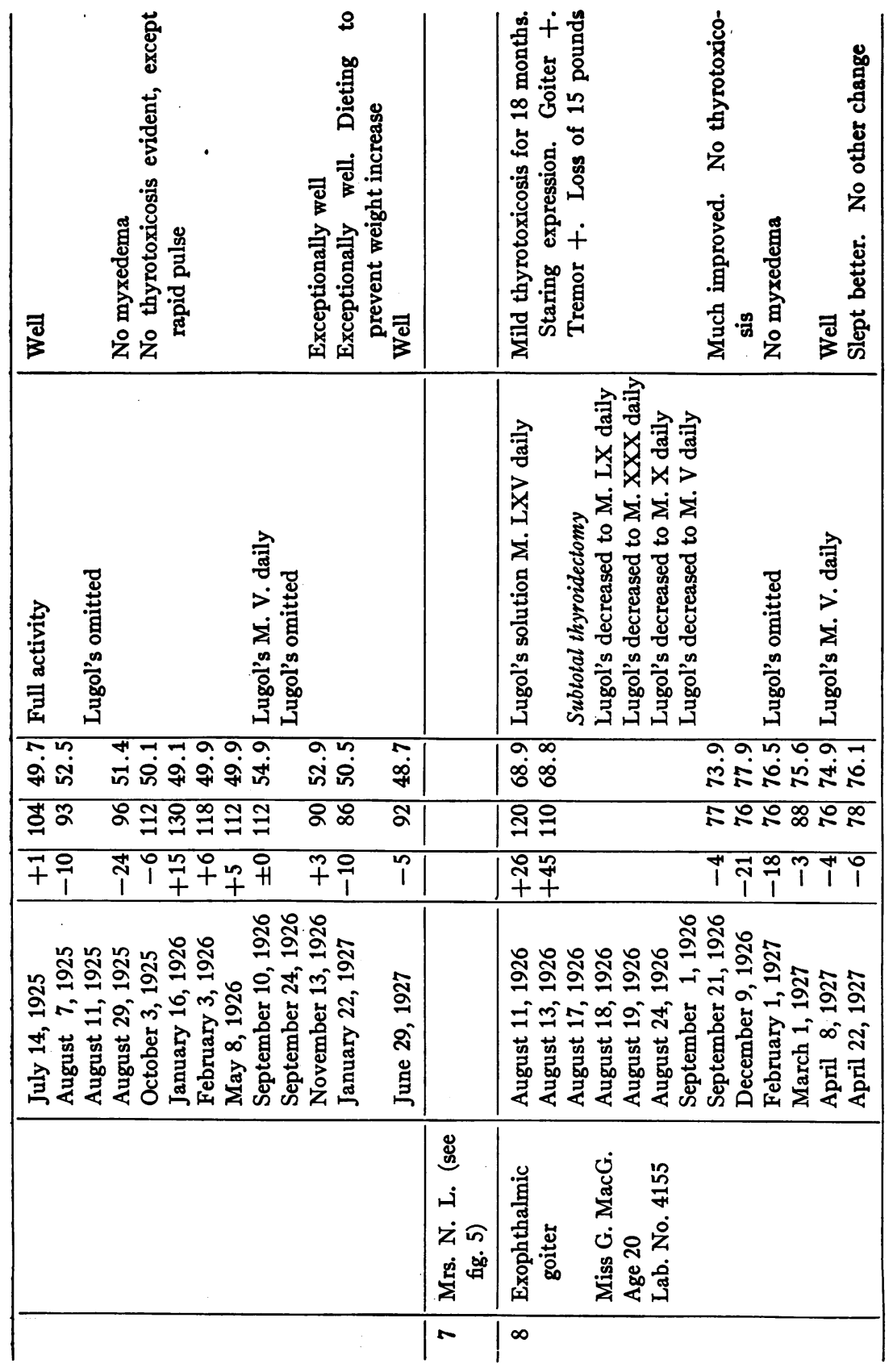




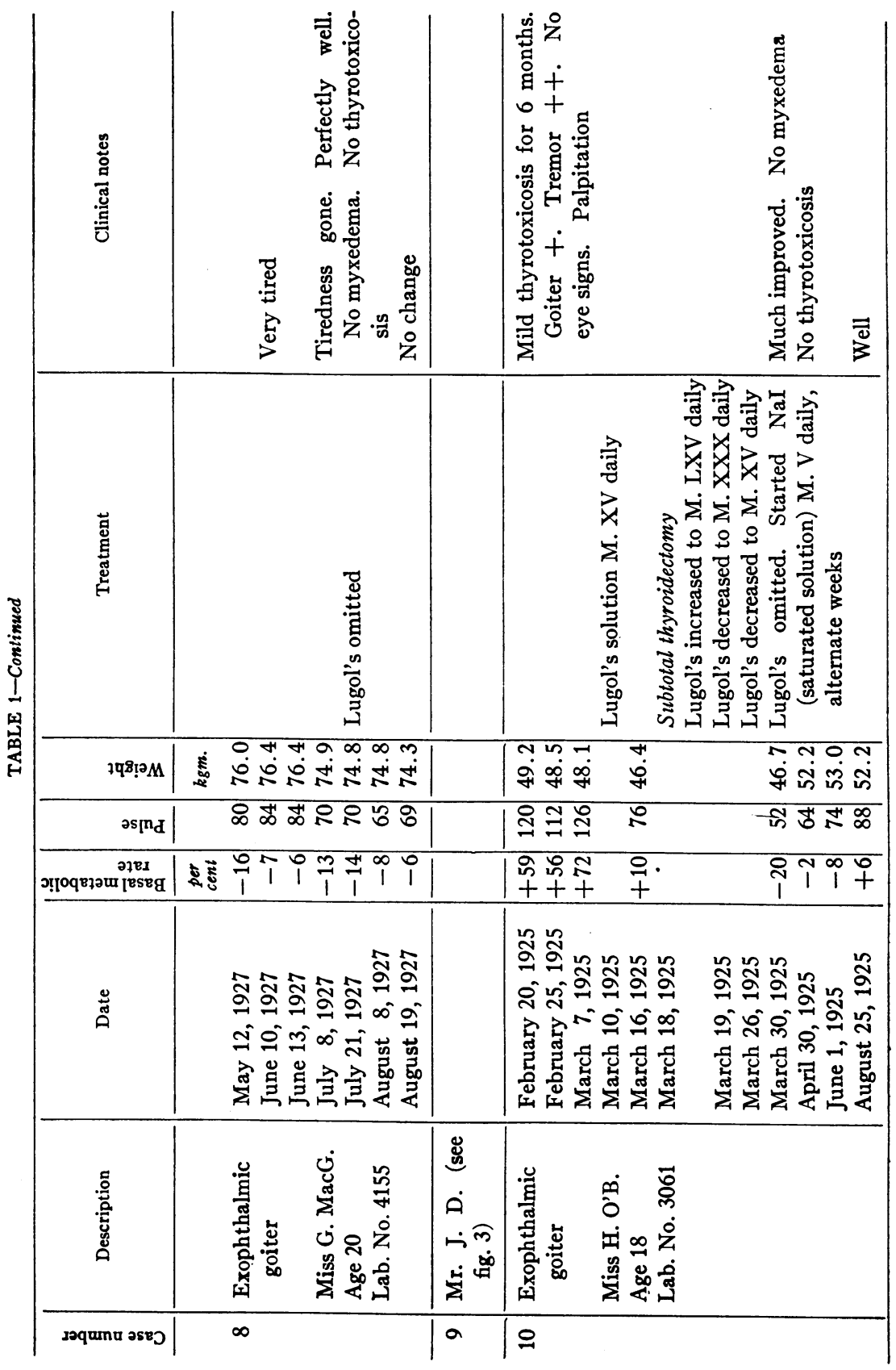


WILLARD OWEN THOMPSON AND PHEBE K. THOMPSON

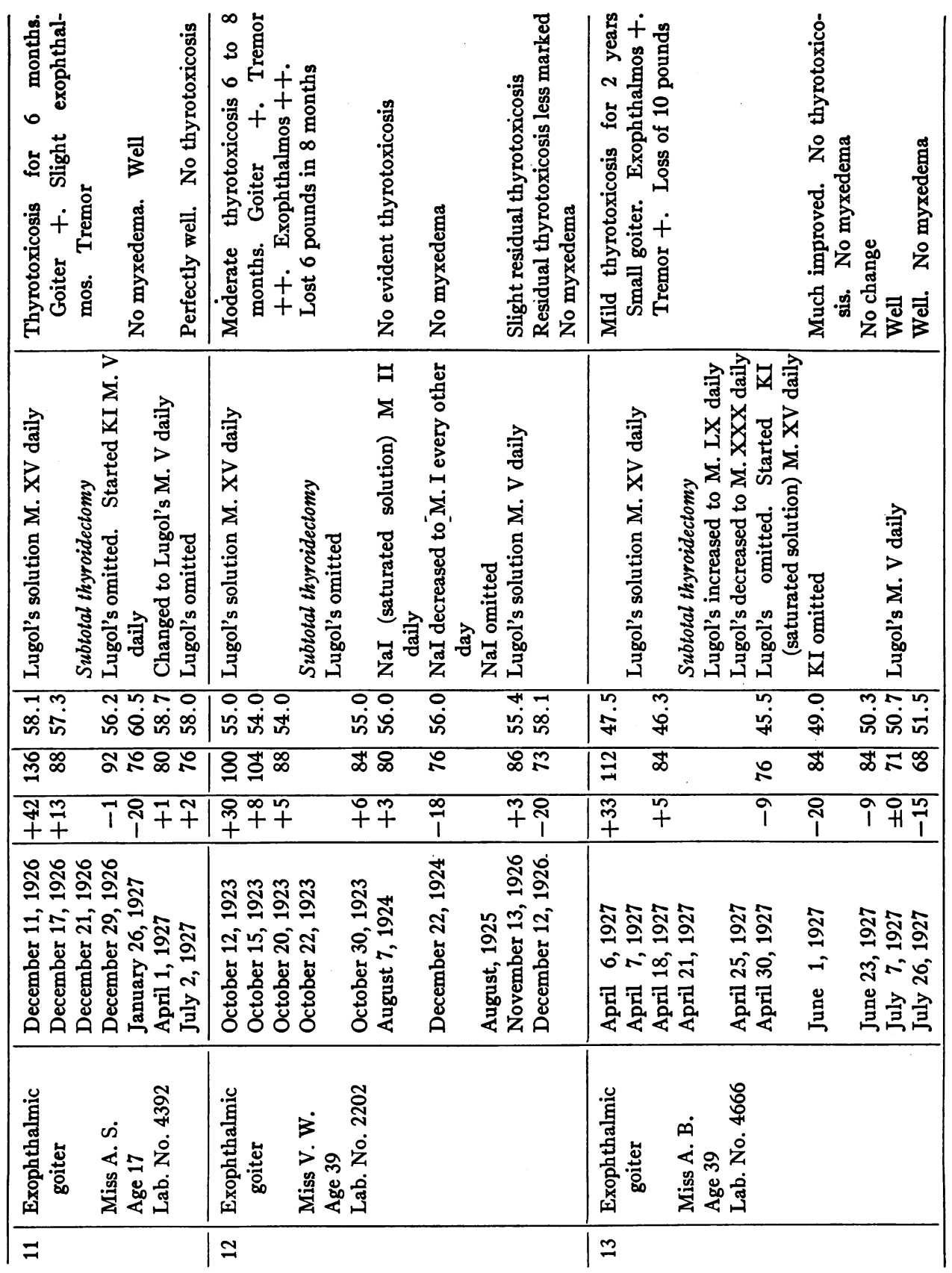




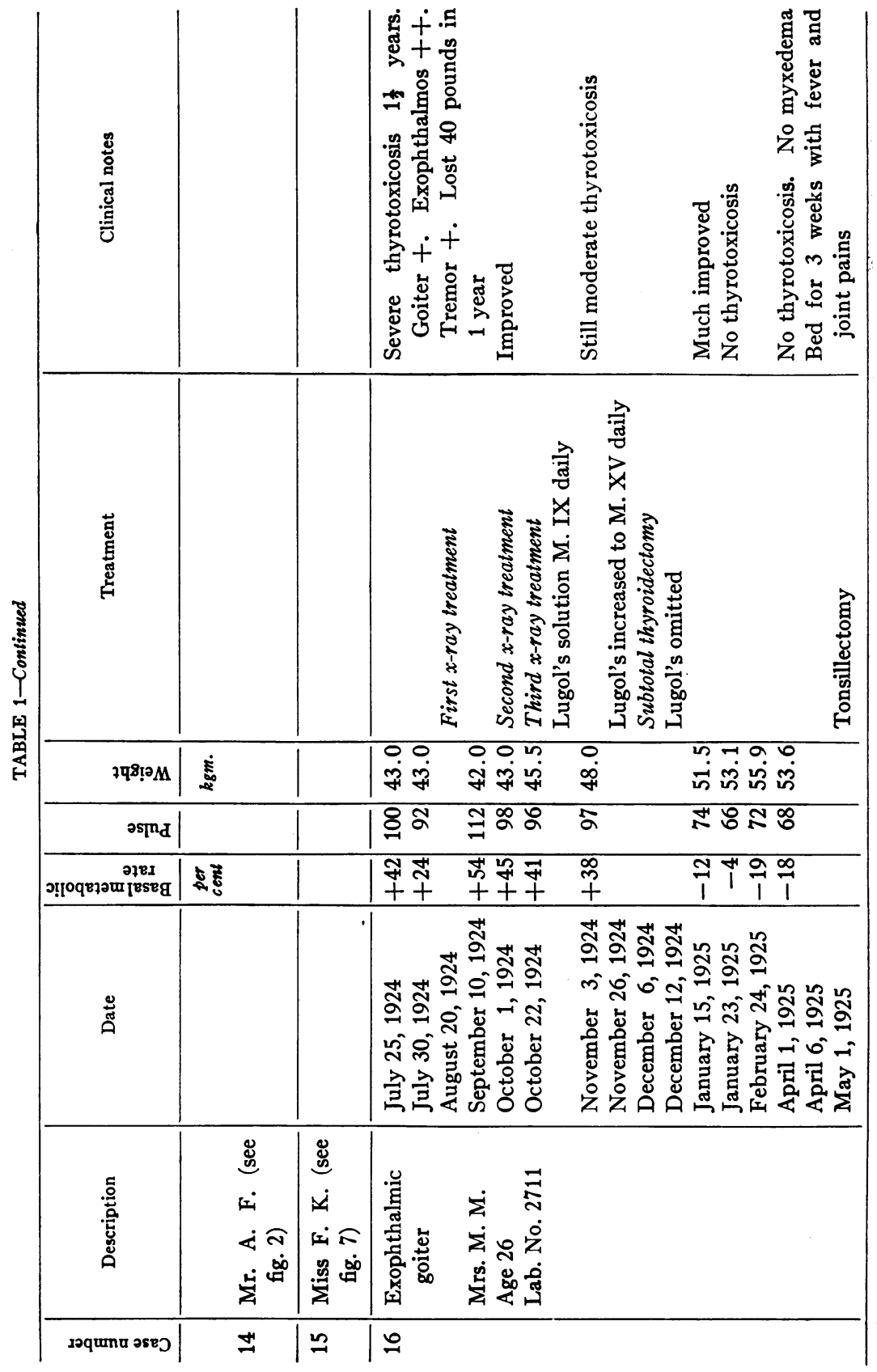




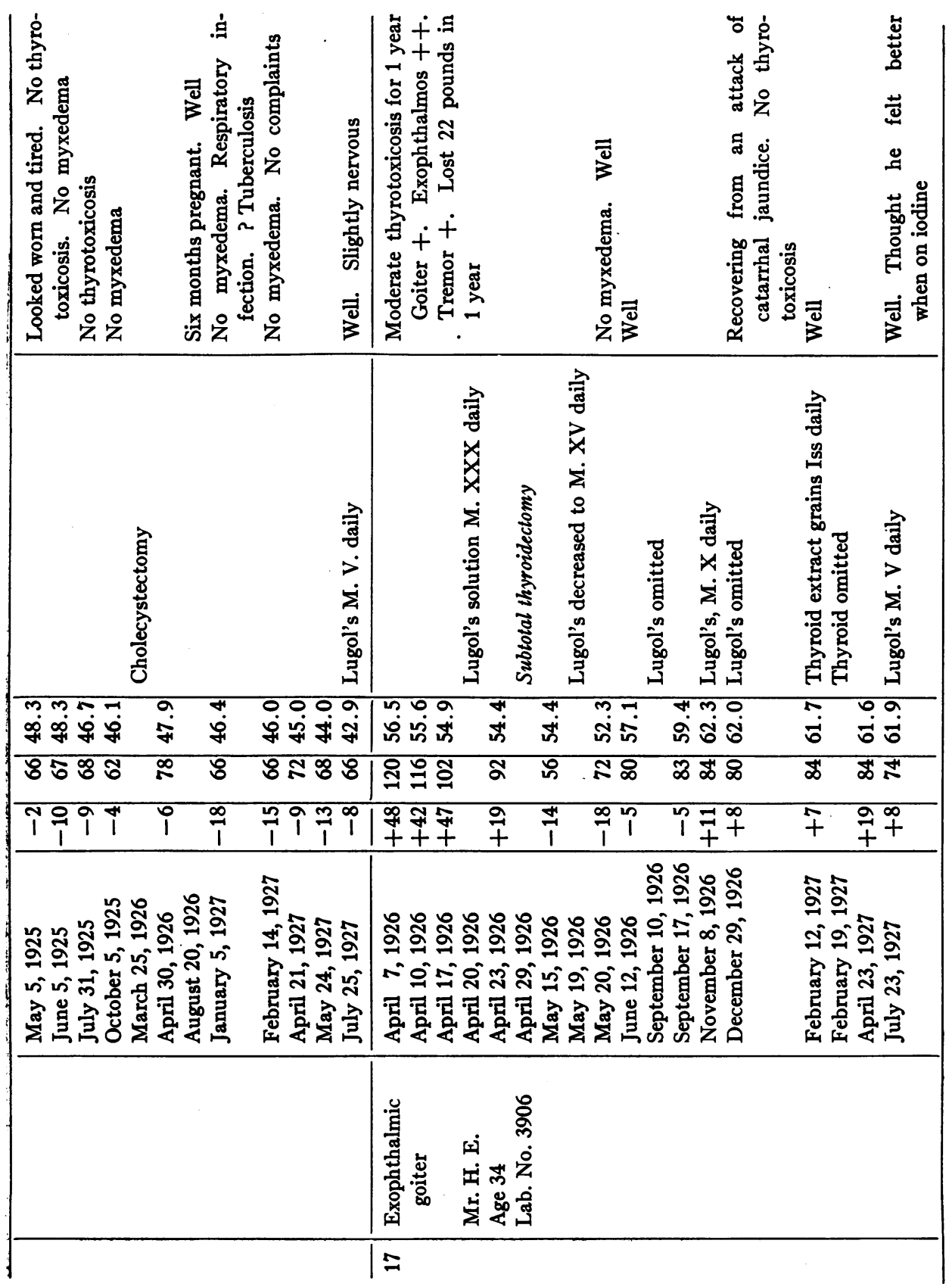




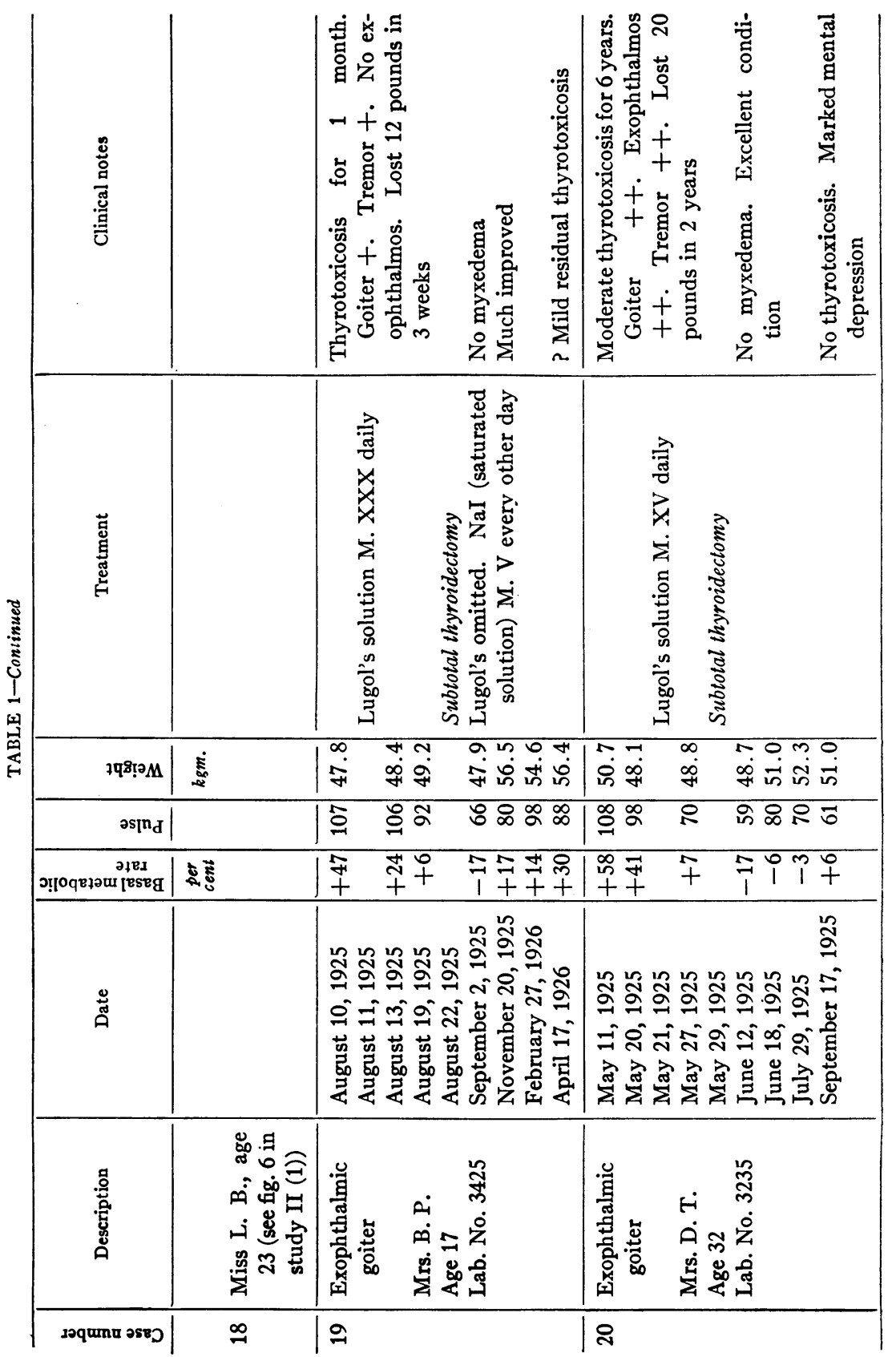




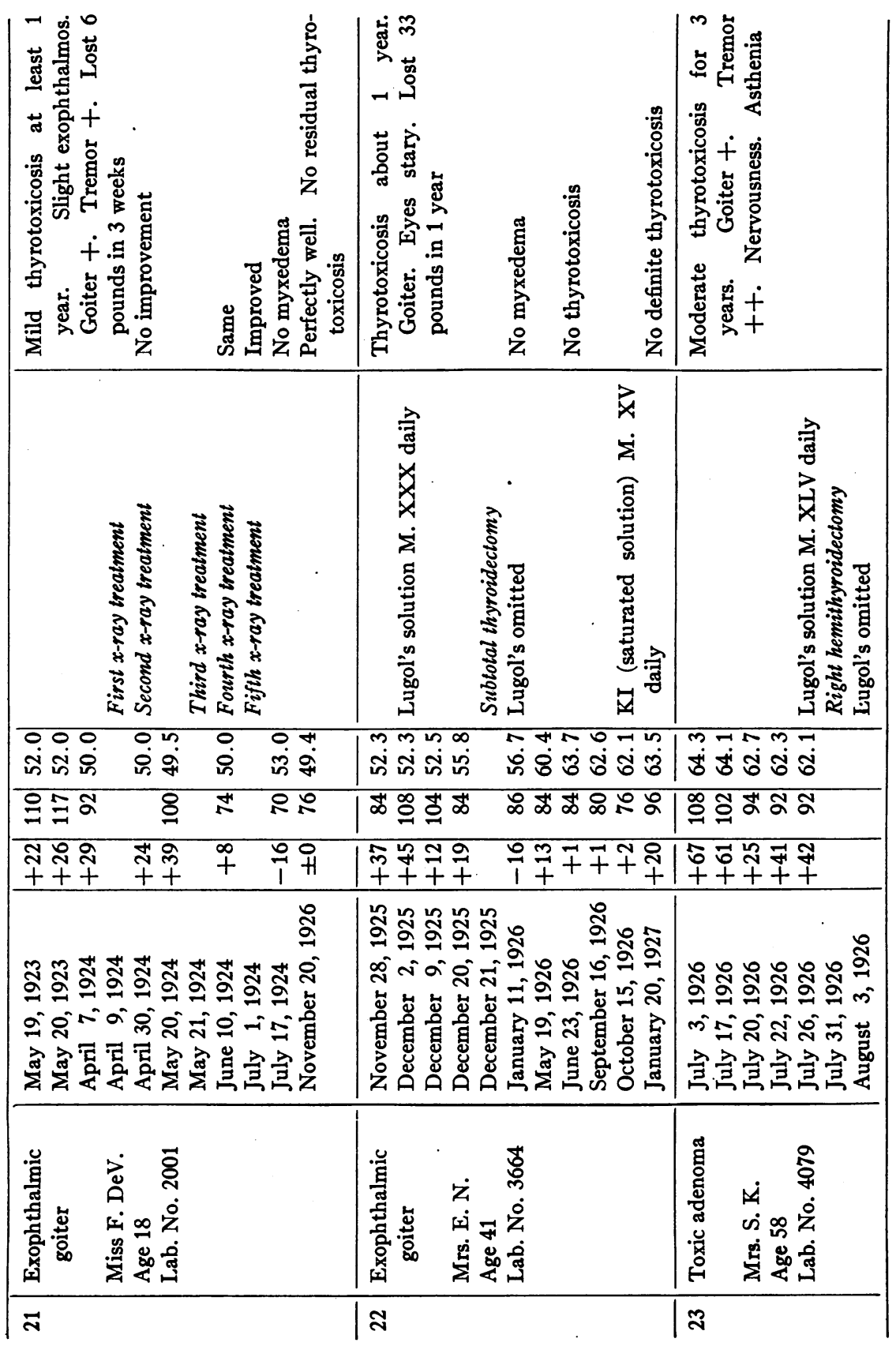




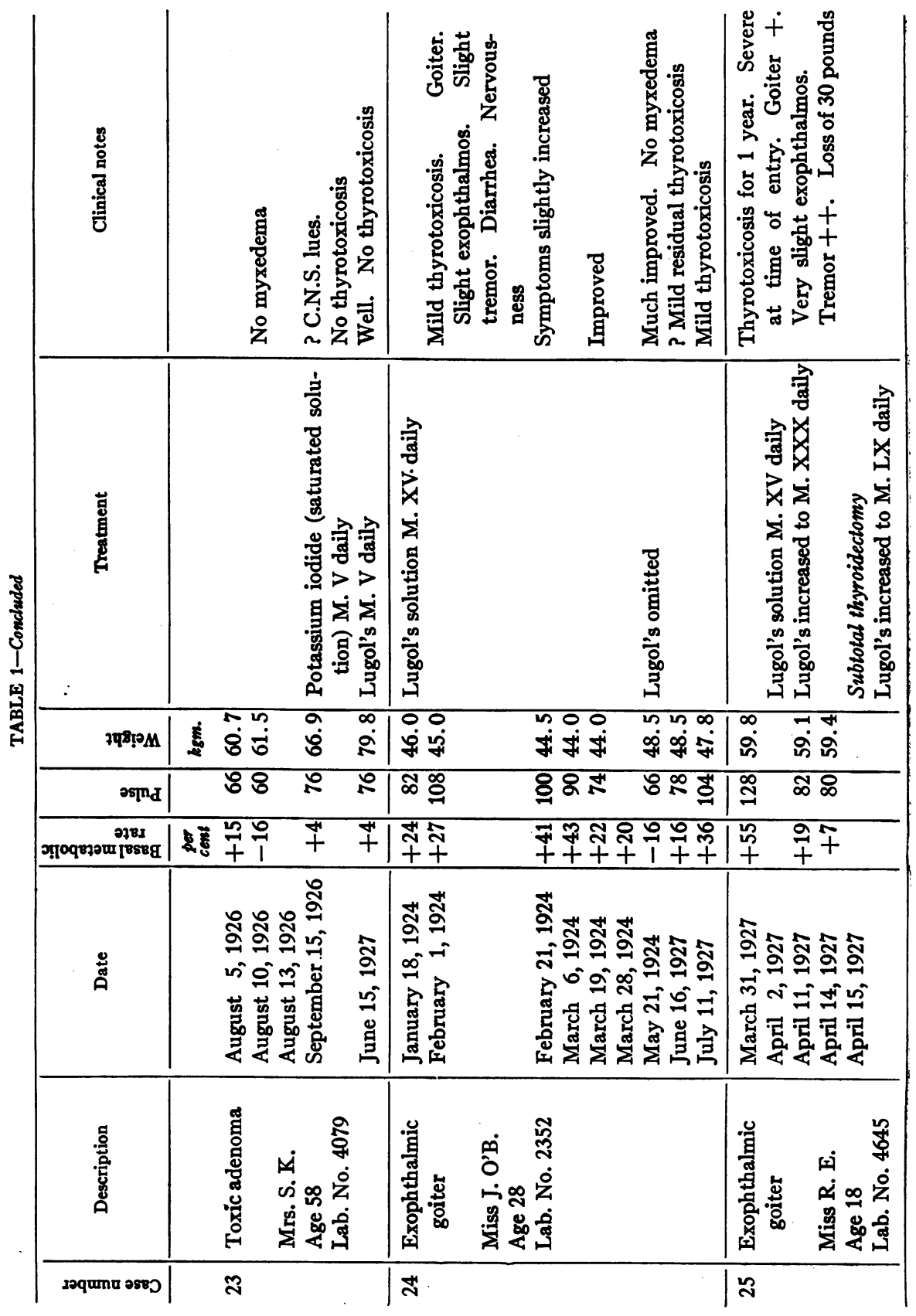


WILIARD OWEN THOMPSON AND PHEBE K. THOMPSON

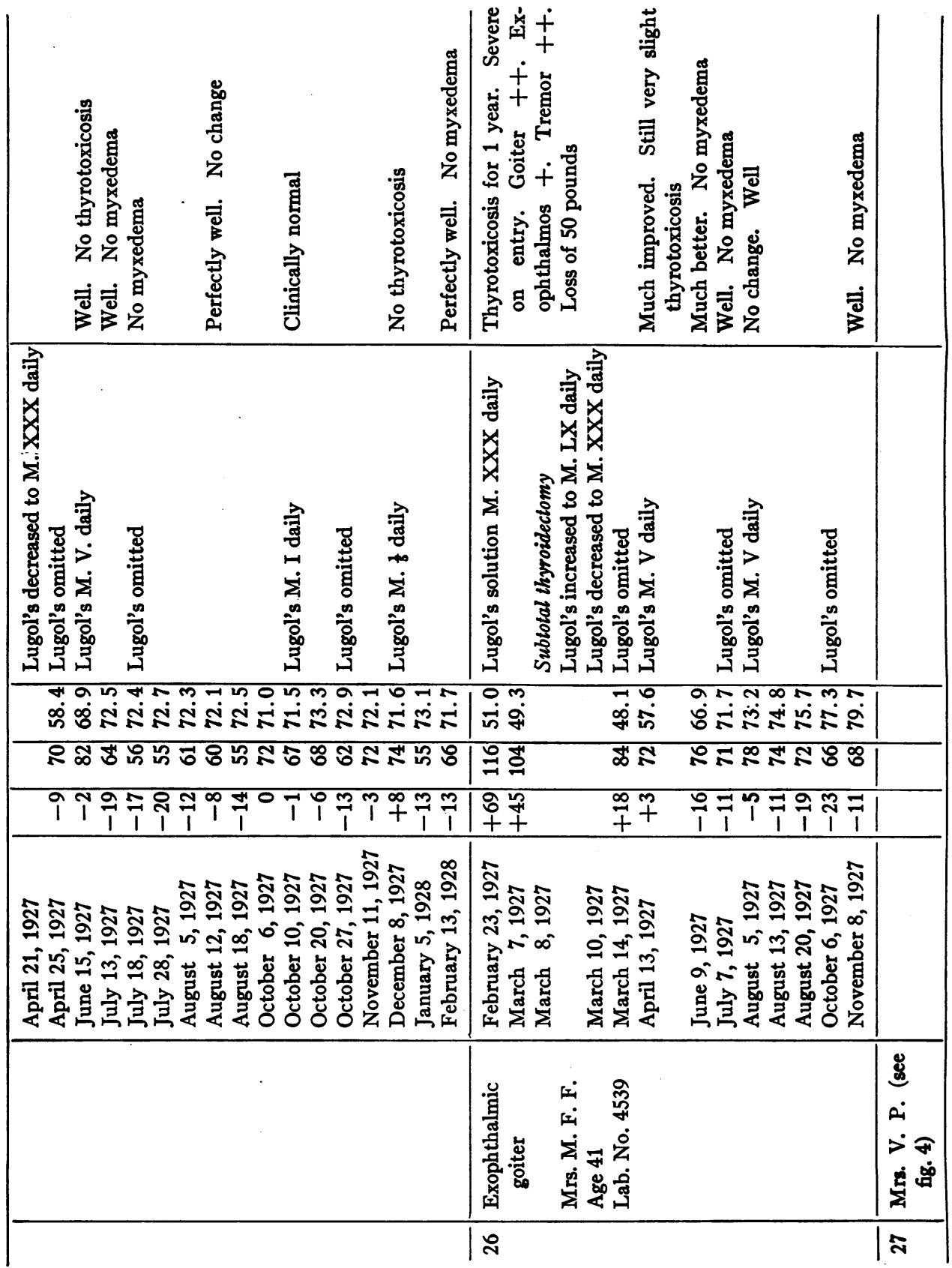


(fig. 4) had rates of minus 44, 38, 33, 25, 25, 24, 23, 21 and 21 per cent respectively, yet they showed no evidence of thyroid underfunction.

Case 7 (fig. 5) illustrates well the typical clinical picture present at the time of the low metabolism: When her metabolism was low (minus

TABLE 2

Time of onset and duration of temporary low metabolism without myxedema

\begin{tabular}{|c|c|c|}
\hline $\begin{array}{c}\text { Number of } \\
\text { cases }\end{array}$ & Time of onset & Duration \\
\hline 10 & Within 1 month after treatment & $\begin{array}{l}1 \text { to } 3 \text { months in } 8 \text { cases } \\
\text { Not accurately known in } 2 \text { cases }\end{array}$ \\
\hline 13 & From 1 to 4 months after treatment & $\begin{array}{l}1 \text { to } 3 \text { months in } 7 \text { cases } \\
4 \text { to } 6 \text { months maximum in } 4 \text { cases } \\
\text { Not accurately known in } 2 \text { cases }\end{array}$ \\
\hline 2 & $\begin{array}{l}\text { From } 4 \text { months to } 1 \text { year after } \\
\text { treatment }\end{array}$ & Not accurately known \\
\hline 2 & Over 1 year after treatment & $\begin{array}{l}4 \text { months maximum in } 1 \text { case } \\
\text { Not accurately known in } 1 \text { case }\end{array}$ \\
\hline
\end{tabular}

TABLE 3

Relation between type of toxic goiter, type of treatment employed for thyrotoxicosis, and temporary low metabolism without myxedema

\begin{tabular}{|c|c|c|c|c|c|c|}
\hline & \multirow{2}{*}{$\begin{array}{c}\text { Iodine } \\
\text { only }\end{array}$} & \multirow{2}{*}{$\begin{array}{c}\begin{array}{c}\text { Subtotal } \\
\text { thyroid- } \\
\text { ectomy }\end{array} \\
\begin{array}{c}\text { On } \\
\text { iodine }\end{array}\end{array}$} & \multirow{2}{*}{$\begin{array}{c}\text { Hemi- } \\
\text { thyroid- } \\
\text { ectomy }\end{array}$} & \multirow{2}{*}{ 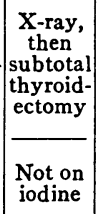 } & \multicolumn{2}{|c|}{ X-ray } \\
\hline & & & & & $\begin{array}{l}\text { On } \\
\text { iodine }\end{array}$ & $\begin{array}{l}\text { Not on } \\
\text { iodine }\end{array}$ \\
\hline $\begin{array}{l}\text { Number of cases of exophthalmic goiter.... } \\
\text { Number of cases of toxic adenoma ........ }\end{array}$ & 2 & 17 & 2 & 2 & 2 & 2 \\
\hline
\end{tabular}

14 to minus 23 per cent) she had no signs or symptoms of myxedema. There was no edema. Her hair and skin were not dry. She was sensitive to cold, but had been so before she developed thyrotoxicosis. She was strong and energetic and not slowed up in any way. She could do her own housework, cooking and washing, and care for two 
children without fatigue. In fact, she was exceptionally well and felt less nervous than when her metabolism was standard normal.

In case 1 (fig. 1) where the metabolism fell to the low level of minus 44 per cent, the absence of clinical evidence of myxedema apparently astonished the observers, as a note in the record states "Very hard to understand."

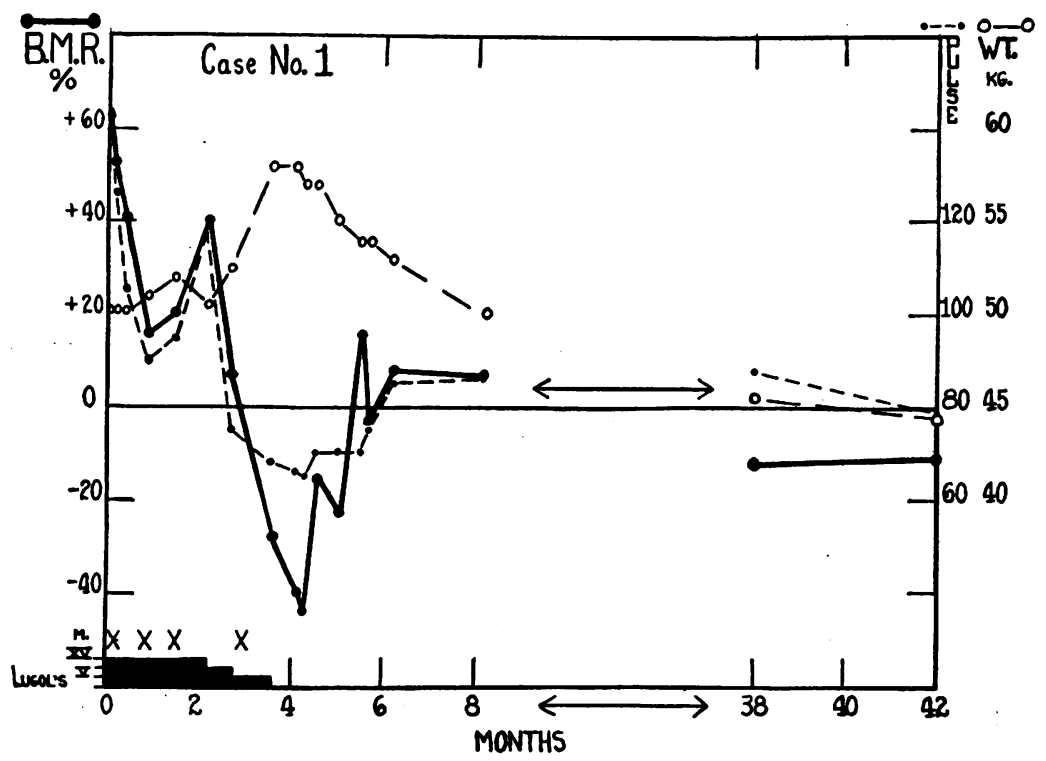

Fig. 1. Mrs. F. A., Age 19. Lab. No. 2160. Temporary Low Metabolic Rate Following X-Ray Treatment $(X)$ and Iodne THERAPY, FOR EXOPHTHALMIC GOITER

No myxedema despite the low level of the metabolism. (In this and subsequent figures, black areas denote Lugol's therapy.)

Influence of type of treatment employed for thyrotoxicosis, with special reference to iodine therapy

As shown in table 3, temporary low metabolism occurs after treatment of thyrotoxicosis by $x$-ray, by subtotal thyroidectomy, or even by hemithyroidectomy alone.

A few cases had no iodine at or near the time of the low metabolic rate (see fig. 2 and fig. 6 in study II (1)), but in the great majority of 
instances the patients were on iodine during this period. A fact worth stressing is that temporary low metabolism may occur after treatment by iodine alone, when there has been no destruction of thyroid gland tissue (see fig. 7).

It is very important to know just what relation iodine therapy bears to these temporary low metabolic rates, for nearly all exophthalmic goiter patients (who constitute the great majority of our series) of

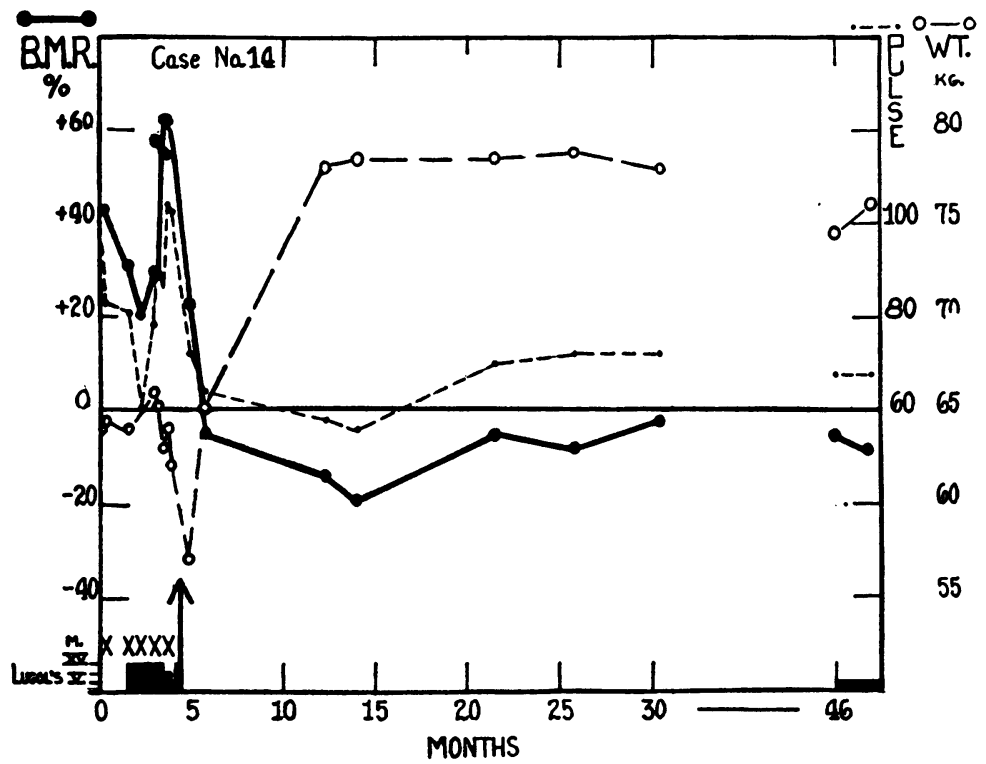

Fig. 2. Mr. A. F., Age 39. Lab. No. 2112. Temporary Low Metabolism OCcurring without Iodine Therapy Eight MONTHS after X-RAy Treatment $(X)$ aNd Subtotal Thyromectomy (arrow) FOR Exophthalmic GOITER

$$
\text { No myxedema }
$$

late years have been put on iodine preoperatively for the express purpose of lowering the metabolism, and this therapy is usually continued for a considerable time after operation, when the influence of thyrotoxicosis has been markedly reduced by surgery.

In an effort to throw some light upon the rôle this medication may play in the production of temporary low metabolism, patients are classified relative to their iodine therapy as shown on following page. 
1. Not on iodine at or near time of low metabolism. The subsequent rise to normal metabolism also occurred without medication. Cases 2, 14 (fig. 2), 16, 18 (fig. 6, study II (1)) and 21. See table 1.

2. Not on iodine at time of lowest metabolism, but iodine omitted so shortly before that it may be a complicating factor. The subsequent rise to normal metabolism occurred without medication. Cases 1 (fig. 1), 6 and 23. See table 1.

3. On iodine at time of low metabolism.

a) The subsequent rise to normal metabolism occurred while still on iodine. Cases 3, 4 (fig. 6), 10, 11, 17, 19 and 20. See table 1.

b) The subsequent rise to normal metabolism occurred on omission of iodine. Cases 5, 7 (fig. 5), 8, 9 (fig. 3), 12, 13, 15 (fig. 7), 22, 24, 25, 26 and 27 (fig. 4). See table 1.

In cases 12 and 13 the metabolism fell to a low level again when iodine was resumed.

Cases 5, 8, 9 (fig. 3) and 26 repeated the cycle of fall and rise coincident with the administration and omission of iodine, for the second time. Cases 7 (fig. 5) and 25 repeated it for the second time and their metabolism fell to a low level again for a third time on iodine. Case 27 (fig. 4) repeated the cycle for the fourth time.

Referring to the above summary of the relationship between temporary low metabolism and iodine therapy, it may be seen that there were 5 cases in which iodine could have played no part in the production of the low rate: and there were 3 cases where the length of time after omission of iodine made its influence somewhat open to question: But there were 19 cases in which the metabolism altered during the period of iodine therapy.

Cases 4 (fig. 6), 7 (fig. 5), 9 (fig. 3), 15 (fig. 7), 24, 25, 26 and 27 (fig. 4) are worthy of special mention in connection with the effect of iodine therapy.

Cases 7, 9 and 27 (figs. 5, 3, and 4 respectively) and cases 25 and 26 (table 1) illustrate particularly well the repeated depression of metabolism to a low level followed by a rise to standard normal, produced by the administration and omission of iodine. In cases 7, 9 and 27 , coincident with the fall in metabolism from standard normal to a low level, nervousness and irritability decreased, the pulse became slower and the weight sometimes increased slightly. They were apparently normal individuals when their metabolism was low, and showed no signs or symptoms of myxedema. Cases 25 and 26, how- 
ever, showed no clinical change coincident with the fall in metabolism from standard normal to a subnormal level, except that in case 25 the pulse became slower. At both levels they appeared to be well.

Case 4 (fig. 6) is of especial interest in that $3 \frac{1}{2}$ years after operation for exophthalmic goiter he showed definite residual thyrotoxicosis with

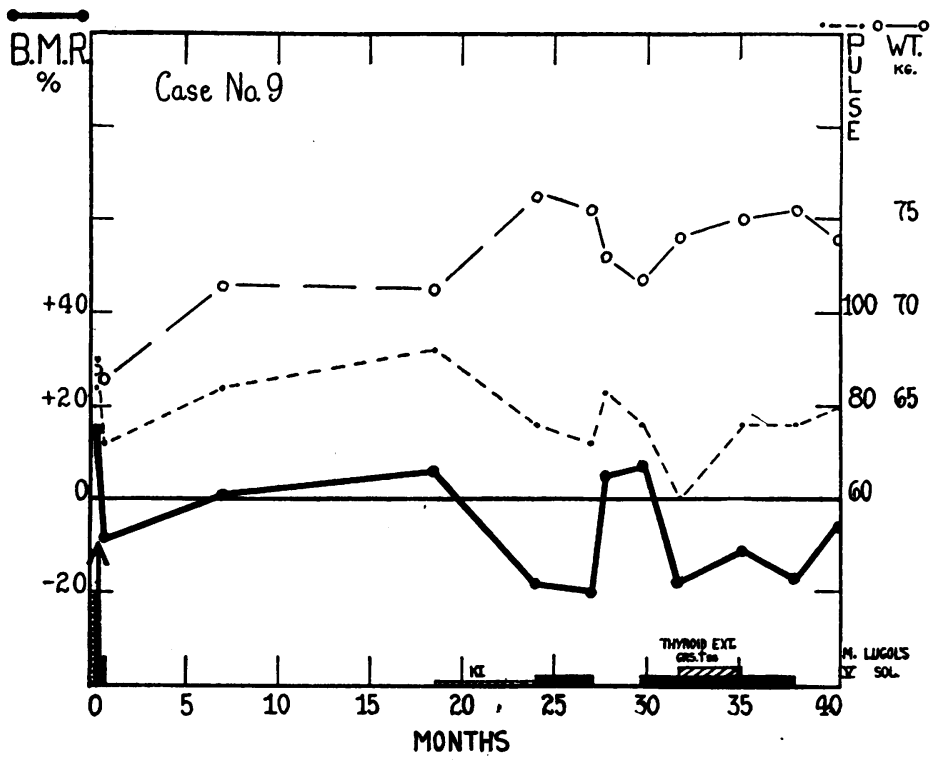

Fig. 3. Mr. J. D., Age 53. Lab. No. 2750. Production of a Temporary Low Metabolism CoINCIDENT With the AdMinistration aNd OMission of ICDine, $1 \frac{1}{2}$ TO $3 \frac{1}{2}$ Years after SUbTOtal ThYromectomy (arROW) FOR ExOPHTHaLMIC GoITER

Relatively low metabolism before operation probably due to KI therapy. Reduction of metabolism to a subnormal level accompanied by decrease of nervousness and irritability. No myxedema although low metabolism lasted many months. Thyroid therapy produced no clinical change. (In this and subsequent figures, cross-hatched areas denote thyroid therapy.)

a metabolism of only plus 4 per cent. He had tremor, exophthalmos, palpitation, increased perspiration, increased appetite and thirst, and marked nervousness and irritability. These signs and symptoms disappeared when his metabolism dropped to minus 25 per cent on iodine, at which time he showed no clinical evidence of myxedema and was 
apparently well. Contrasting him with cases 7,9 and 27, it may be noted that the latter were evidently in a steady state of thyrotoxicosis and their metabolism fell to about the same level each time iodine was given. In case 4 on the other hand, the thyrotoxicosis appeared to be increasing, coincident with a marked increase in the amount of palpable thyroid tissue, and the level to which iodine depressed his metabolism gradually rose.

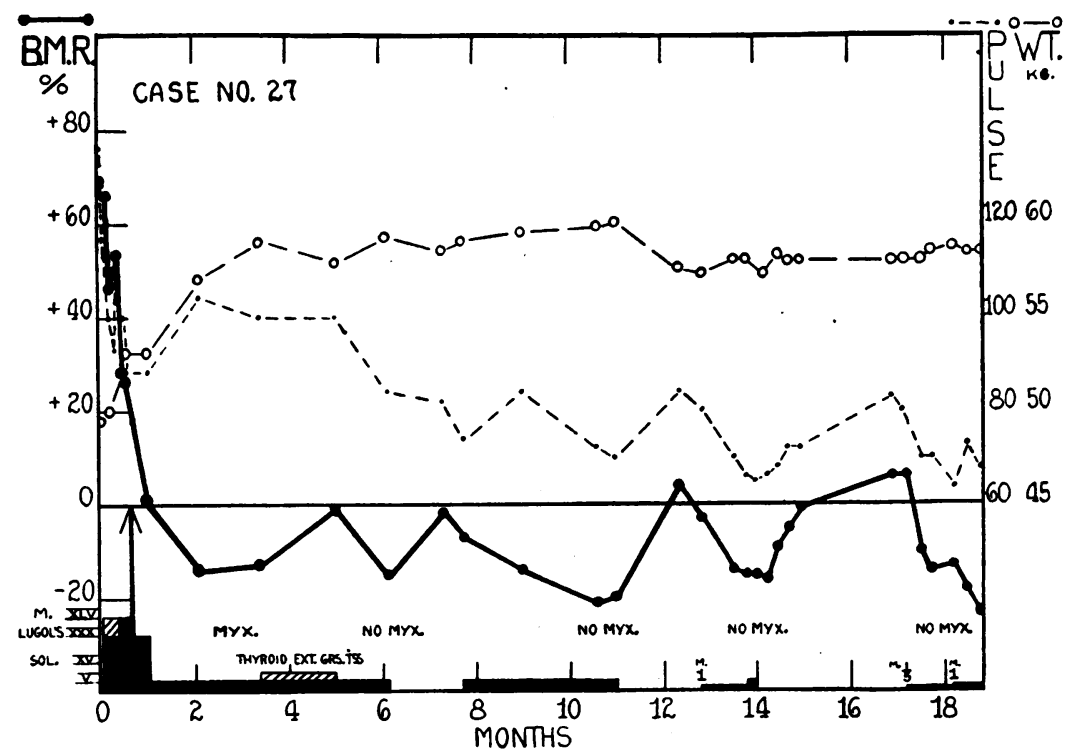

Fig. 4. Mrs. V. P., Age 30. Lab. No. 4001. Repeated Production of Temporary Low Metabolism Concident with the Administration and OMission of Iodine, following SUbTotal Thyroidectomy (arRow) FOR EXopHTHALMIC GoITER

Nervousness decreased with each metabolic depression. No myxedema except mild temporary type at the time of the first low metabolism.

Cases 15 (fig. 7) and 24, two cases of mild but typical exophthalmic goiter, are outstanding because iodine was the only form of treatment they received for thyrotoxicosis, yet their metabolism fell to a subnormal level, coincident with clinical improvement, on this medication alone. Since collecting this data we have observed the same phenomenon in 2 other cases. 
Although there are cases in our series in which iodine was not a factor, the cases elaborated above indicate that iodine can play an important rôle in these temporary metabolic depressions. There is also some suggestive statistical evidence upholding this opinion. On looking up the statistics for 1920 as an example of a year when iodine was not in use as an aid to surgery, it was found that at least 10 per

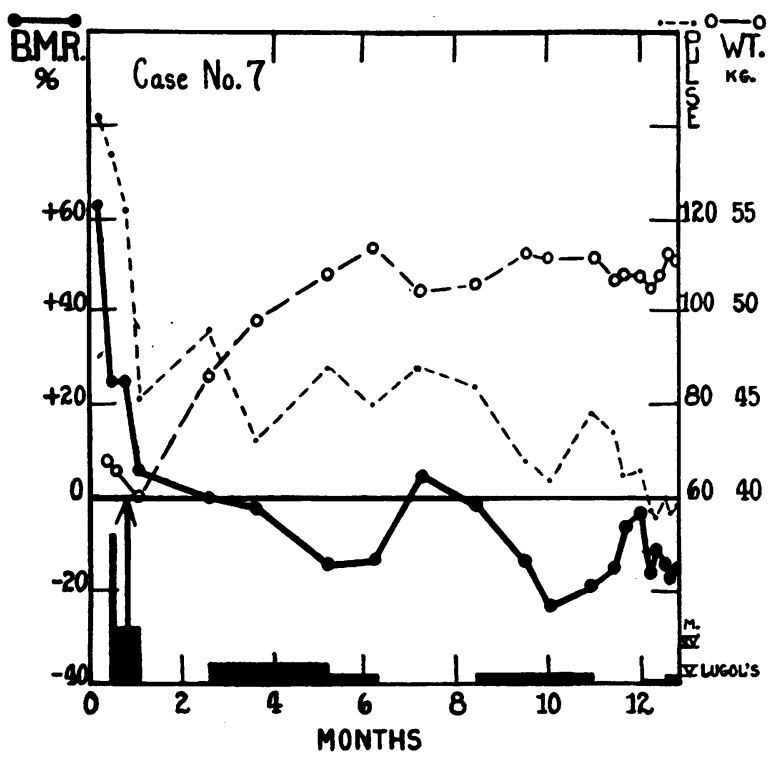

Fig. 5. Mrs. N. L., Age 23. Lab. No. 4102. Also Showing Repeated ProDUCTION OF TEMPORARy LOW METABOLISM COINCIDENT WITH THE ADMINISTRATION AND OMISSION OF IODINE FOLLOWING SUbTOTAL THYROIDECTOMY (ARROW) FOR EXOPHTHALMIC GOITER

As in figures 3 and 4, nervousness decreased with each metabolic depression. No myxedema.

cent of treated toxic goiter patients developed low metabolic rates, but they were all of the permanent type. The inference is that the use of iodine is the cause of the increase in incidence to about 25 per cent in the years 1925 and 1926, which increase was due mainly to the addition of the temporary type. We are of the opinion that if iodine were not in use, temporary low metabolism would be observed much less frequently. 


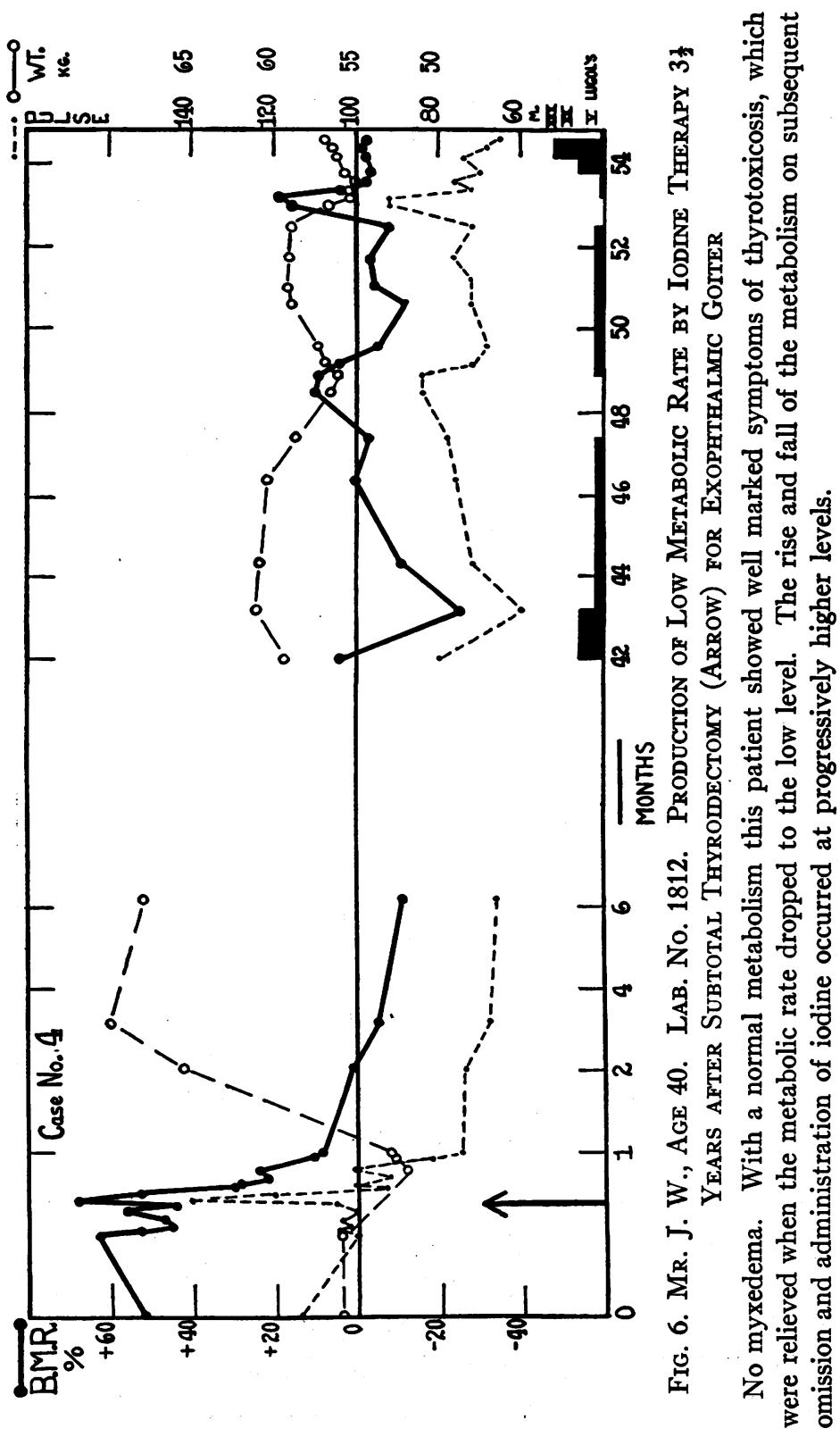




\section{DISCUSSION}

The absence of myxedema in the cases in this study during the period of temporary low metabolism has already been stressed. Hence, if the low metabolism be due to an insufficiency of thyroid secretion, it must be an insufficiency not detectable clinically. There is some reason to suppose that such a clinical state may exist for a short time. We have been much impressed by the length of time

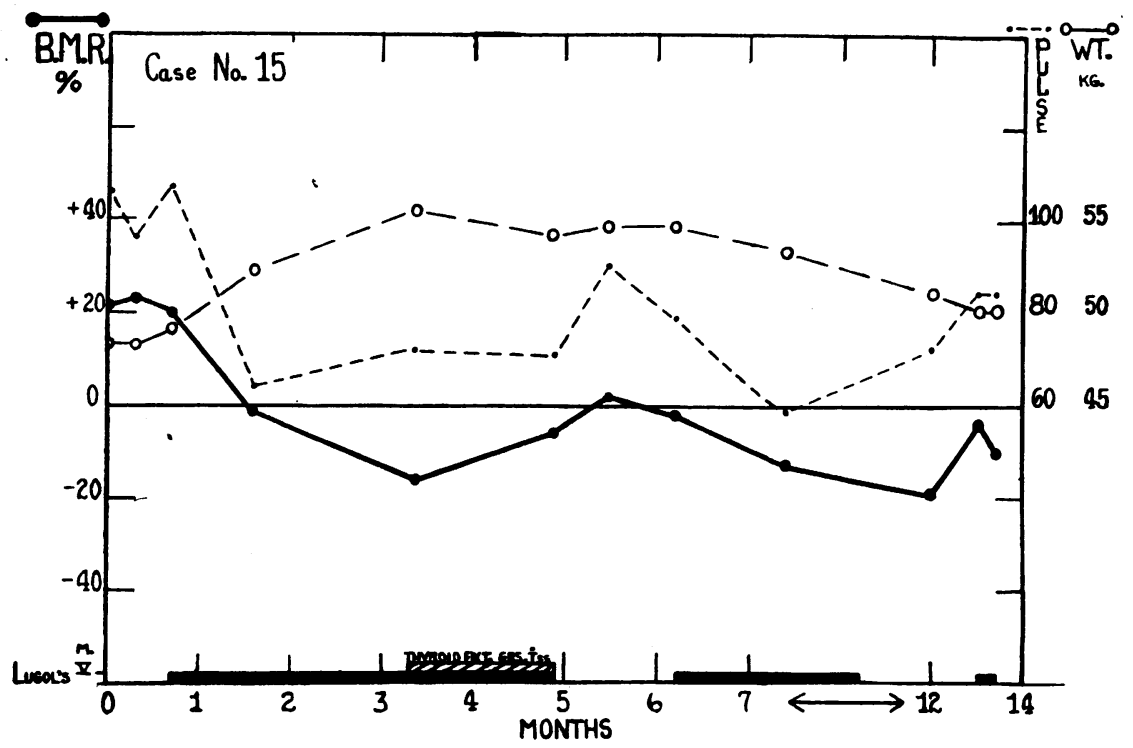

Fig. 7. Miss F. K., Age 17. Lab. No. 4034. Production of Low Metabolism by the USE of Iodine as the OnLy Type of Treatment in a

Case of Mild Exophthalmic Gotter

No myxedema

necessary for some of our cases of once marked spontaneous myxedema to show any clinical effects of omission of thyroid extract, after they had been kept normal by it for years. It has taken as long as 5 months in one instance. The effect on metabolic rate was noticeable before the clinical effect, nevertheless it also was slow in appearing. It is possible that in some of our cases there was a deficiency of thyroid secretion which lasted for such a short time that the effect was noticeable only on the metabolism and not on the clinical picture. 
While very small amounts of normal thyroid tissue can keep the body sufficiently supplied with the thyroid hormone, it must be borne in mind that in the cases presented, the gland is a diseased one. It may be that, after treatment, the diseased gland remnant becomes suddenly overburdened and requires a certain length of time to adjust itself to altered working conditions. During this period of adjustment, a mild lack of thyroid secretion might explain the temporary low metabolism in those patients who had a subtotal thyroidectomy.

In view of the considerations just presented, we feel that some of our cases can be satisfactorily accounted for by a period of temporary thyroid insufficiency, not detectable clinically. This will be referred to later.

The hypothesis of a temporary hypothyroidism, however, does not satisfactorily explain:

1. The striking effect of iodine in repeatedly depressing the metabolism to a subnormal level months to years after operation, coincident with clinical improvement of some signs and symptoms of mild thyrotoxicosis.

2. The production of a low metabolism by iodine alone when no other form of therapy was used for treatment of thyrotoxicosis.

3 . The development of temporary low metabolism after the removal of only half the thyroid gland. (Four-fifths to seven-eighths of the thyroid may be removed in most cases of toxic goiter without depressing the metabolism to a low level.)

4. The occurrence of the low metabolism many months to a few years after operation, and the absence of myxedema in the cases where it lasted many months (fig. 3).

Adjustment of the gland remnant, if it did take place, would naturally occur immediately after operation, and could scarcely account for the onset of a temporary low rate a long time afterwards.

5. The fact that temporary low metabolism without myxedema was followed by permanent low metabolism without myxedema in one instance (case 18, fig. 6 in study II (1)).

In connection with the effect of iodine therapy, it is important to note that this medication does not appear to affect the metabolism of normal individuals (4) (5) (6) (7), although Marine (8) has made a few observations which suggest that, in a few instances, heat production 
may be lowered in normal rabbits by the use of large doses. Careful work on a large series of cases is required in order to settle this point beyond doubt. Present data favor the opinion that iodine therapy does not lower the metabolism of normal people. It may thus be fairly assumed that the depression of the metabolism to a subnormal level by iodine in our cases is associated with the control of thyrotoxicosis. Since no symptoms of myxedema appear, even when the metabolism remains low for several months, it may also be fairly assumed that, in controlling this thyrotoxicosis, iodine does not cause a thyroid insufficiency.

Marine (8) believes that iodine acts in exophthalmic goiter by producing an excess of colloid which blocks the secretion. Such a theory would account for the action of iodine in our series on the basis of a temporary hypothyroidism. This theory appears to be improbable, however, for the following reasons:

1. The action of iodine in exophthalmic goiter is well marked before much change in the consistency of the gland has occurred, and is often complete before the storage of colloid reaches its maximum.

2. We have seen the metabolism rise when iodine was continued after producing its usual remission, in spite of the persistence of such an excess of colloid that the gland was stony hard.

The foregoing considerations lead up to a second explanation for temporary low metabolism, which appears to be more adequate than temporary hypothyroidism to account for many of our cases. The assumption is that the normal basal metabolism of the patients concerned is low. A certain number of normal people who have never had thyrotoxicosis have a basal metabolism in the vicinity of minus 16 to minus 25 per cent: consequently a low metabolism without myxedema occurring after treatment for toxic goiter may be explained very well as a drop to the patient's normal level, similar to that commonly occurring in a patient whose normal level is in the vicinity of zero. Just as the latter phenomenon is probably increased in incidence by the use of iodine during the immediate post-operative period, so also is the former. Just as patients whose metabolism drops to its normal level of about zero often develop, especially if iodine be omitted, a slightly elevated metabolism of about plus 20 per cent, with no very definitely discernible symptoms of thyrotoxicosis, so also may 
patients whose metabolism drops to its normal low level of about minus 20 per cent shortly develop the same clinical picture, with a metabolic rate of about zero. This may occur in spite of iodine therapy, but is much more likely to occur if iodine be omitted. It may occur also, in the natural course of events, when iodine has never been used at any time. Then, just as in the first group, this residual thyrotoxicosis may eventually burn itself out, allowing the metabolism to return to the vicinity of zero, so also may the same train of events occur in the latter group, allowing the metabolism to return to its normal level of about minus 20 per cent. Accordingly, some of our temporary low rate cases without myxedema, which at present show a standard normal metabolism may eventually develop a permanent low metabolism without myxedema, as is very definitely suggested by case 18 (see fig. 6 in study II (1)).

The hypothesis that a metabolism below the standard normal level may be normal for some individuals will be discussed in more detail in the paper on permanent low metabolism without myxedema (1).

There are a few cases in our series which seem to be exceptions to this hypothesis, i.e., those in which the metabolism was below minus 25 per cent. We have never seen individuals who could be considered normal with a metabolic rate lower than this. Thus, in at least these cases, the transient low rate appears to be explained best by a temporary lack of normal thyroid secretion, not detectable clinically. The same explanation may also hold for a few of the cases in which the lowest metabolism recorded was above minus 25 per cent.

The number of cases in which the low metabolism was due to temporary hypothyroidism and the number in which it represented the normal metabolic level of the patient, can be definitely determined only by following the patients until their metabolism has reached a stationary level.

Aside from attempting to explain the significance of temporary low metabolism and the mechanism by which it may occur, there is a point of minor interest brought out by the data collected, viz., in connection with thyroid therapy. In view of the striking lack of myxedema in our group of cases, we wish to emphasize the importance of treating the signs and symptoms of that deficiency rather than the metabolic rate. In the past, patients with a metabolic rate below 
minus 15 per cent have often been assumed to have myxedema, and they have in many instances been put on thyroid extract merely because of the reduced metabolism, even though there were no signs nor symptoms of hypothyroidism. This medication has been sometimes continued unnecessarily for years, because the possible lack of correlation between the low metabolism and myxedema was not recognized, aside altogether from the fact that the low metabolism itself might be only temporary.

\section{SUMMARY}

Twenty-seven cases have been presented showing temporary low metabolism (minus 16 to minus 44 per cent) without myxedema, following treatment for thyrotoxicosis.

The usual time of onset of this low metabolism was within 4 months after treatment, although in a few cases it was from 1 to $3 \frac{1}{2}$ years afterwards. The usual duration was about 1 to 4 months.

During the period of low metabolism, most of the patients appeared to be normal individuals.

It occurred after $x$-ray therapy and after subtotal and hemithyroidectomy.

In 5 cases there was no iodine therapy during the period of low metabolism: in 7 cases, the metabolism both fell and rose on iodine; and in 15 cases (including 2 in which neither surgery nor x-ray therapy was employed) the metabolism fell on iodine and rose when it was omitted. In some of the latter cases, months to years after operation, the metabolism could be made to fluctuate at will from a standard normal to a subnormal level and back again, by the administration and omission of iodine.

In some instances, signs and symptoms diagnostic of or suggestive of mild thyrotoxicosis, which were present with a standard normal metabolic rate, disappeared when iodine was given and the metabolism dropped to a subnormal level.

\section{CONCLUSION}

In some cases, temporary low metabolism without myxedema following thyrotoxicosis appears to be due to a period of thyroid insuffi- 
ciency not detectable clinically. In others, it appears to represent a transient return to the patient's normal metabolic level, the subsequent rise to standard normal metabolism representing a period of mild recurring thyrotoxicosis.

\section{BIBLIOGRAPHY}

1. Thompson, W. O., and Thompson, P. K., Jour. Clin. Invest., 1928, v, 471. Low Metabolism Following Thyrotoxicosis. II. Permanent Type without Myxedema.

2. Thompson, W. O., and Thompson, P. K., Jour. Clin. Invest., 1928, v, 441. Myxedema Following Thyrotoxicosis.

3. Jordan, S. M., Arch. Surg., 1925, xi, 1. Basal Metabolic Rates and Their Relation to End Results in Thyroid Disease: A Statistical Study.

4. Strouse, S., and Binswanger, H. F., J. A. M. A., 1927, lxxxviii, 161. The Symptom Complex Resembling Hyperthyroidism without Increased Metabolism.

5. Segall, H. N., Unpublished data.

6. Martin, K. A., Am. Jour. Med. Sci., 1927, clxxiv, 648. The Conditions under Which Iodin Will Cause a Change in the Basal Metabolic Rate in Man. I. Its Occurrence in Conditions Other than That of Graves' Disease.

7. Thompson, W. O., and Thompson, P. K., Unpublished data.

8. Marine, D., Deutch, M., and Cipra, A., Proc. Soc. Exper. Biol. and Med., 1927, xxiv, 657. The Effect of Large Doses of Iodine on Heat Production in Rabbits. 